\title{
Corrigendum
}

\section{Corrigendum to "Resource Tardiness Weighted Cost Minimization in Project Scheduling”}

\begin{abstract}
Ali Shirzadeh Chaleshtari
Department of Industrial Engineering, College of Engineering, West Tehran Branch, Islamic Azad University, Tehran, Iran

Correspondence should be addressed to Ali Shirzadeh Chaleshtari; shirzadeh.a@wtiau.ac.ir

Received 18 March 2017; Accepted 27 April 2017; Published 12 July 2017

Copyright (C) 2017 Ali Shirzadeh Chaleshtari. This is an open access article distributed under the Creative Commons Attribution License, which permits unrestricted use, distribution, and reproduction in any medium, provided the original work is properly cited.
\end{abstract}

In the article titled "Resource Tardiness Weighted Cost Minimization in Project Scheduling" [1], the affiliation of the author was given incorrectly. The correct affiliation is shown above.

\section{References}

[1] A. Shirzadeh Chaleshtari, "Resource tardiness weighted cost minimization in project scheduling," Advances in Operations Research, vol. 2017, Article ID 1308704, 11 pages, 2017. 


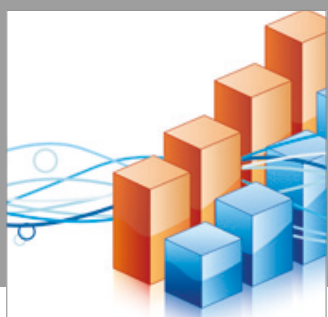

Advances in

Operations Research

vatersals

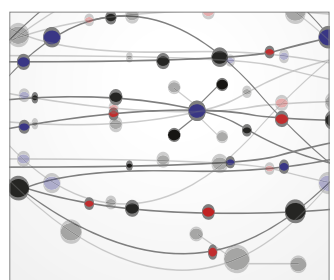

\section{The Scientific} World Journal
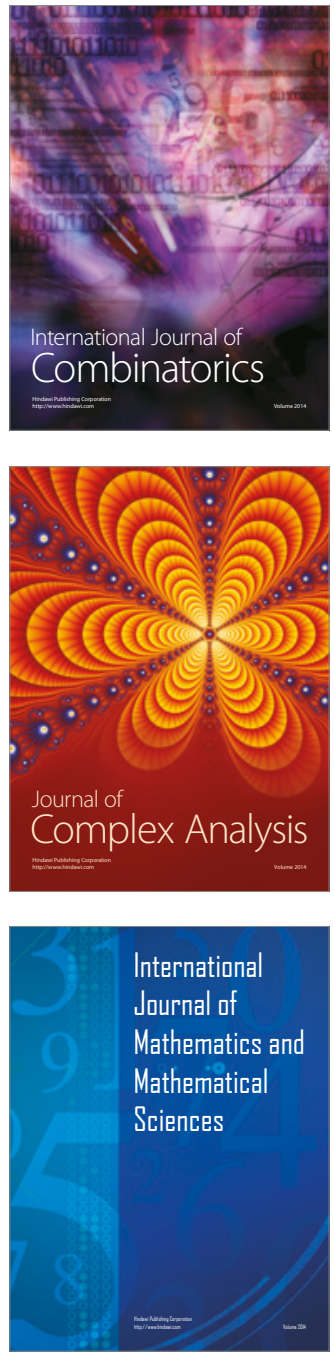
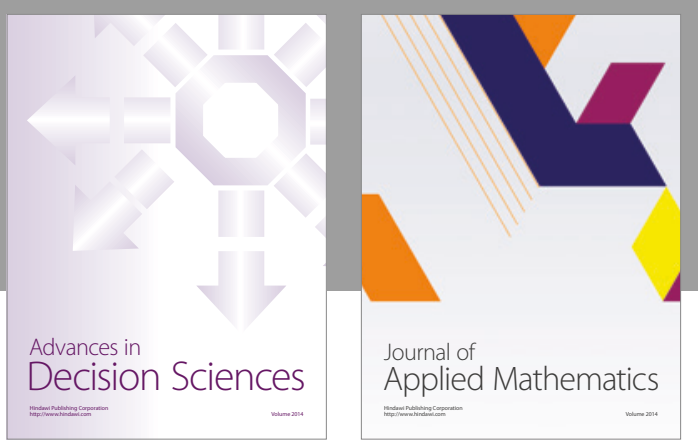

Algebra

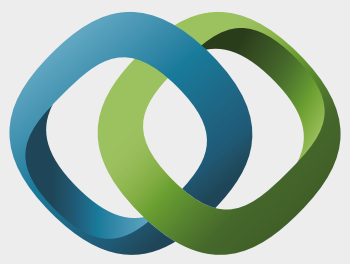

\section{Hindawi}

Submit your manuscripts at

https://www.hindawi.com
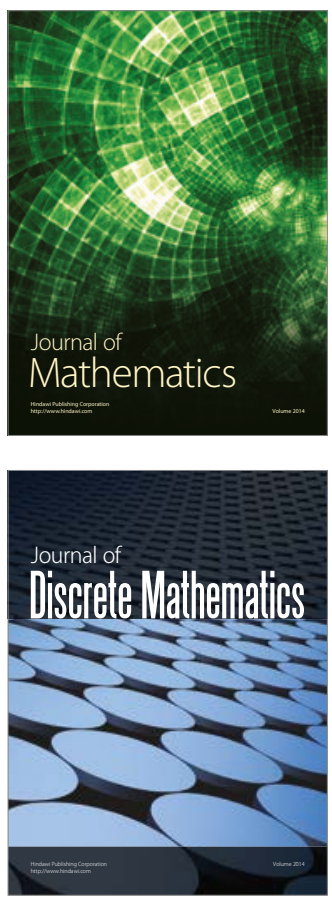

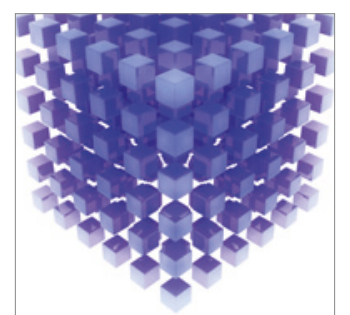

Mathematical Problems in Engineering
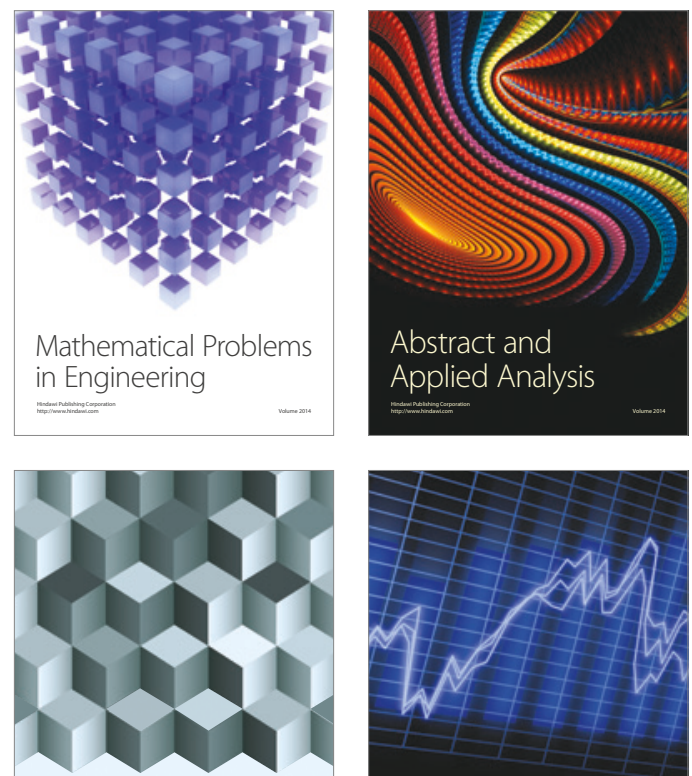

Journal of

Function Spaces

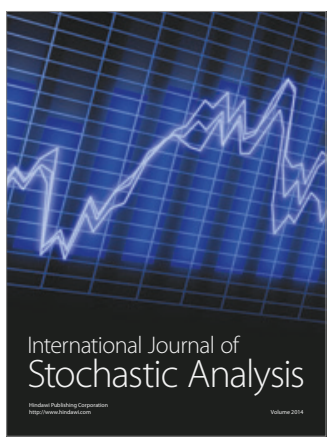

Probability and Statistics
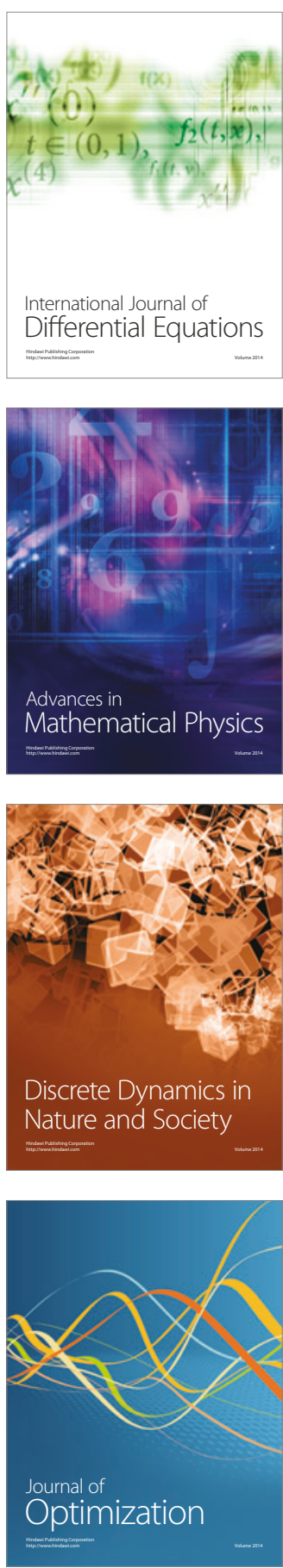